\title{
Developmental Ability of Mouse Late 2-Cell Stage Blastomeres Fused to Chemically Enucleated Oocytes in vitro
}

\author{
Adil S. ELSHEIKH, Yoshiyuki TAKAHASHI, Mitsugu HISHINUMA, and Hiroshi KANAGAWA \\ Laboratory of Theriogenology, Department of Veterinary Clinical Science, Graduate School of Veterinary Medicine, Faculty of \\ Veterinary Medicine, Hokkaido University, Sapporo 060, Japan
}

(Received 18 July 1996/Accepted 21 October 1996)

\begin{abstract}
The effects of different concentrations of etoposide and cycloheximide (ETO-CHXM), used for chemical enucleation of mouse oocytes, on polar body extrusion and chromatin expulsion were tested. The developmental ability of blastomeres of late 2-cell stage embryos fused to chemically enucleated oocytes of different ages or cytoplasts from different sources was also examined in vitro. Metaphase I oocytes cultured in different concentrations of ETO-CHXM (10-50 $\mu \mathrm{g} / \mathrm{m} l$ each) extruded polar bodies at rates similar to those cultured without ETO-CHXM (58.5-65.9\% and 64.6\%, respectively). However, low percent of the oocytes (1.7-6.2\%) expressed signs of meiotic perturbation, which was manifested by blebbing of the cytoplasmic membrane and extrusion of two or more polar bodylike fragments. Twenty-three percent of the chemically enucleated oocytes cultured in ETO-CHXM-free medium spontaneously fused to their polar bodies. The rates of total chromatin expulsion were similar when ETO-CHXM concentrations were $36 \mathrm{and} 50 \mu \mathrm{g} / \mathrm{ml}(93.5 \mathrm{and}$ $98 \%$, respectively). The results also showed that the cleavage rates of reconstituted embryos were significantly $(\mathrm{P}<0.001)$ affected by the age of the chemically enucleated oocytes. Cytoplasts of bisected oocytes that matured in vivo supported the development of $31.7 \%$ of the reconstituted embryos to the blastocyst stage. However, both cytoplasts of chemically enucleated oocytes and in vitro matured oocytes did not support development to the blastocyst stage. A high percentage $(85.5 \%)$ of the reconstituted embryos with chemically enucleated recipients displayed abnormality of the metaphase plate. These results suggest that concentrations of etoposide between 36 and $50 \mu \mathrm{g} / \mathrm{m} l$ are optimum for enucleation of mouse oocytes. Furthermore, increasing the age or reducing the cytoplasmic volume of the chemically enucleated oocytes did not improve the development of the reconstituted embryos to the blastocyst stage. - KEY wORDs: chemical enucleation, cytoplast source, mouse, reconstituted embryo.
\end{abstract}

J. Vet. Med.Sci. 59(2): 107-113, 1997

Finding an economical source of competent recipient cytoplasm is a problem that has slowed down the progress of nuclear transplantation and embryo cloning [19, 20-23, 34]. The current methods for obtaining recipient cytoplasts include: a) blind aspiration of metaphase II (M II) oocyte chromosomes with cytoplasm of the polar body area [14], b) bisection of M II oocytes [25, 26, 32], c) micromanipulation of M II oocytes under a fluorescent microscope after staining the chromosomes with fluorescent dyes [9], or using fluorescent dyes and ultraviolet irradiation after micromanipulation to confirm the total removal of the chromosomes [22], and d) centrifugation of zona-free oocytes [28, 33].

These procedures are complicated by several problems: (a) the first polar body sometimes migrates far away from the M II chromosomes and as the oocyte ages, the chromosomes have a tendency to migrate towards the center of the oocyte [20]; (b) since these procedures utilize cytoskeletal inhibitors, the quality of the enucleated cytoplasm varies considerably depending on the kind of cytoskeletal inhibitor used, and time of exposure to the cytoskeletal inhibitor [24]; (c) ultraviolet irradiation affects the maturation promoting factor (MPF), which is recognized as the biological entity responsible for remodeling and reprogramming of the donor nuclei [1]; and (d) the bulk of the MPF is associated with the nuclear apparatus [3], which is usually removed during the enucleation process. Under these circumstances, some specific factors associated with chromatin could be removed or inactivated during these procedures. Thus, the quality and quantity of recipient cytoplasm vary not only from technique to technique but also from person to person.

Fulka and Moor [6] recently described a novel approach to enucleate mouse oocytes chemically at metaphase I using etoposide (ETO) and cycloheximide (CHXM). The obvious advantage of chemical enucleation is in terms of the speed of the enucleation process which overcomes the difficulties of micromanipulation. However, it was reported that perturbing mitosis induces abnormal mitosis in mammalian cells $[4,12]$. The same phenomena might occur during meiotic perturbation and be harmful to the oocytes.

Thus, before using chemically enucleated oocytes for embryo reconstitution and nucleocytoplasmic interaction studies, further investigation and refinement of this technique is needed. The present study was designed to examine the effects of different ETO and CHXM (ETOCHXM) concentrations on maintaining binding and enhancing chromosome expulsion of mouse oocytes. Since the activation response of the reconstituted embryos is related to the age of the recipient oocyte [23], the study also examined the influence of the age of chemically enucleated oocytes as recipient cytoplast on in vitro development of reconstituted embryos obtained by fusion of late 2-cell stage blastomeres with intact chemically enucleated oocytes. Reconstituted embryos obtained by fusion of late 2-cell stage blastomeres to cytoplasts from bisected oocytes are reported 
to develop to the blastocyst stage [26]. Therefore, the study also compared the developmental ability of reconstituted embryos when cytoplasts of bisected chemically enucleated oocytes were used as recipients, with recipient cytoplasts obtained by bisection of oocytes matured in vivo and in vitro.

\section{MATERIALS AND METHODS}

Oocytes and embryos: Six-week-old females of the ICR and F1 (C57BL/6J X CBA) mice strains were injected intraperitoneally with 5 IU of pregnant mare serum gonadotropin (PMSG; serotropin; Teikoku Zoki, Tokyo, Japan). Oocytes at the germinal vesicle $(\mathrm{GV})$ stage were collected from both ICR and F1 females by puncturing the antral follicles $46-48 \mathrm{hr}$ after PMSG injection. To collect oocytes matured in vivo, F1 females were injected intraperitonealy with $5 \mathrm{IU}$ of human chorionic gonadotropin (hCG; gonatropin; Teikoku Zoki) $48 \mathrm{hr}$ after PMSG and ovulated oocytes were collected $14-16 \mathrm{hr}$ later by puncturing the ampullae of the oviducts in Whitten's medium [31] supplemented with $100 \mu \mathrm{M}$ EDTA (WM + EDTA). In all experiments, the cumulus cells were removed from GV and M II oocytes by pipetting with a narrow pipette. Oocytes matured in vitro were obtained at the M II stage after culture of GV oocytes from F1 females in WM + EDTA for $17 \mathrm{hr}$. Late 2-cell stage embryos were collected from ICR females superovulated with PMSG and hCG and mated with males of the same strain by flushing of the oviducts with WM + EDTA at 46-48 hr after hCG injection.

Chemical enucleation: Chemical enucleation was carried out basically as described by Fulka and Moor [6,7]. Briefly, the GV intact oocytes of F1 females were cultured in WM + EDTA for $6 \mathrm{hr}$; thereafter, oocytes that had undergone germinal vesicle breakdown (GVBD) were transferred into $\mathrm{WM}+$ EDTA containing $50 \mu \mathrm{g} / \mathrm{m} l$ ETO and cultured for 2 hr. At the end of this treatment, they were transferred into $\mathrm{WM}+$ EDTA with ETO and CHXM (50 $\mu \mathrm{g} / \mathrm{m} l$ each) and cultured for 10-12 hr until the polar bodies were extruded. The extrusion of the polar bodies was assumed to be the endpoint of enucleation (see Experiments 2 and 3).

Bisection of oocytes: Bisection of the oocytes was carried out as described by Tarkowski and Rossant [27] with slight modifications. Briefly, after the removal of zonae with acid Tyrode's solution ( $\mathrm{pH} 3$ ) [10], the oocytes were cultured in Dulbecco's phosphate-buffered saline (PBS) containing 3 $\mathrm{mg} / \mathrm{m} l$ bovine serum albumin (BSA) and $5 \mu \mathrm{g} / \mathrm{m} l$ cytochalasin B (CB; Sigma Chemical Co., St. Louis, MO, U.S.A.) for $30 \mathrm{~min}$. They were then transferred to the dissecting medium PBS + BSA and $\mathrm{CB}$, and pipetted with a pipette of 20-30 $\mu \mathrm{m}$ internal diameter into cylindrical rods and dissected manually using a fine glass needle on a surface of $1 \%$ agar [27]. For dissection of oocytes matured in vivo and in vitro into cytoplasts and karyoplasts, the polar body was used as an indicator for the presumed localization of the oocyte chromosomes.

Blastomere-cytoplast agreggation: Zonae of the 2-cell stage embryos were removed with acid Tyrode's solution. Blastomeres of 2-cell embryos were isolated by pipetting zona-free embryos in $\mathrm{Ca}^{2+}$-free PBS. The zonae of intact chemically enucleated oocytes were removed with acid Tyrode's solution and their polar bodies were separated by pipetting. The cytoplasts from intact chemically enucleated or bisected chemically enucleated, and bisected oocytes matured in vivo or in vitro were aggregated with the isolated donor blastomeres in $10 \mu \mathrm{g} / \mathrm{m} l$ phytohemagglutinin solution (Difco Laboratories, Detroit Michigan, U.S.A.) in PBS [16]. To increase the area of contact between the aggregated cytoplasts and donor blastomeres they were pipetted with a narrow-bore pipette.

Electrofusion, activation and embryo culture: The aggregated blastomere-cytoplast pairs were cultured in WM + EDTA for 30-45 min and electrofused as described by Elsheikh et al. [5]. The electrofusion parameters were an alternating current with a field pulse of $0.6 \mathrm{MHz}$ and voltage of $5 \mathrm{~V} / \mathrm{mm}$ applied for $5 \mathrm{sec}$ to induce alignment and to bring the blastomere-cytoplast membranes in direct contact using 3 direct current pulses (1-sec interval), with a pulse strength of $70 \mathrm{~V} / \mathrm{mm}$ and $70 \mu \mathrm{sec}$ pulse duration. The fusion medium was PBS. The fused embryos were activated at 60-90 min after fusion with 7\% ethanol in WM + EDTA for $5 \mathrm{~min} \mathrm{[30].} \mathrm{The} \mathrm{fused} \mathrm{embryos} \mathrm{and} \mathrm{single} \mathrm{control}$ blastomeres of the late 2-cell stage were cultured in $25 \mu \mathrm{l}$ of $\mathrm{WM}+$ EDTA in multiwell plates (Sumitomo Bakelite Co., Tokyo, Japan) for $96 \mathrm{hr}$ at $37^{\circ} \mathrm{C}$ in an atmosphere of $5 \%$ $\mathrm{CO}_{2}$ in air. The development of the fused embryos and the control embryos was assessed every $12 \mathrm{hr}$ under an inverted microscope.

Experiment 1: The effects of different ETO-CHXM concentrations on maintaining binding and enhancing chromosome expulsion were examined. From ICR mice, oocytes of considerable size and clear GV were cultured for $6 \mathrm{hr}$ in Waymouth medium (Gibco Laboratories, New York, U.S.A.) supplemented with 5\% fetal calf serum [29]. Thereafter, the oocytes that underwent germinal vesicle breakdown (GVBD) were cultured for $2 \mathrm{hr}$ in Waymouth medium containing $50 \mu \mathrm{g} / \mathrm{m} l$ ETO as described by Fulka and Moor [6, 7]. They were further cultured in Waymouth medium with different concentrations of ETO-CHXM (10, 25,36 and $50 \mu \mathrm{g} / \mathrm{ml}$ each) for $12 \mathrm{hr}$. The oocytes were classified under a dissecting microscope into three categories, oocytes with polar bodies, without polar bodies and with budding or blebbing of the cytoplasmic membrane. Enucleated oocytes with ETO-CHXM $(50 \mu \mathrm{g} / \mathrm{ml})$ were cultured in ETO-CHXM-free WM + EDTA for $12 \mathrm{hr}$. Control oocytes with GVBD were cultured in ETO-CHXMfree Waymouth medium for $14 \mathrm{hr}$. After fixation in aceto-ethanol and staining with aceto-lacmoid or acetoorcein, their chromatin content was examined under a light microscope.

Experiment 2: The influence of the age of chemically enucleated oocytes on in vitro development of reconstituted embryos was investigated. Germinal vesicle oocytes of F1 mice were chemically enucleated as mentioned above. 
Oocytes with polar bodies were thoroughly washed in WM + EDTA and classified into three groups. They were cultured in drug-free WM + EDTA, for 4-8 hr (group 1), for $15 \mathrm{hr}$ (group 2) or for $24 \mathrm{hr}$ (group 3). After the removal of zonae and polar bodies, the enucleated oocytes were aggregated and fused with the isolated donor blastomeres of late 2-cell stage embryos. Fusion was assessed $30 \mathrm{~min}$ after the fusion treatment. Some of the reconstituted embryos were cultured for $96 \mathrm{hr}$, and their development to blastocysts was examined. When chemically enucleated oocytes cultured for $15 \mathrm{hr}$ were used as recipients, reconstituted embryos were cultured after fusion for 60-90 min in WM + EDTA, fixed with aceto-ethanol and stained with acetoorcein to examine the normality of the metaphase plate.

Experiment 3: This experiment was carried out to compare the in vitro development of reconstituted embryos obtained by fusion of single blastomeres of late 2-cell stage embryos into cytoplasts from bisected chemically enucleated oocytes and bisected oocytes matured in vivo and in vitro. Germinal vesicle oocytes of F1 mice were chemically enucleated as mentioned above and cultured for $15 \mathrm{hr}$ in drug-free WM + EDTA and they were then bisected into two cytoplasts. Germinal vesicle oocytes of F1 mice were matured in vitro in drug-free WM + EDTA for $17 \mathrm{hr}$ and then bisected as mentioned above. Oocytes matured in vivo (collected from F1 females at 14-16 hr after hCG injection) were bisected as described above. The cytoplasts were aggregated and fused with donor blastomeres of late 2-cell stage embryos and cultured for $96 \mathrm{hr}$, and their development to the blastocyst stage was examined.

Statistical analysis: Data were analyzed by Fisher's exact test. Probability values $<0.05$ were considered to be significant.

\section{RESULTS}

Experiment 1: The rates of polar body extrusion were not affected by the concentration of ETO-CHXM (Table 1). The process of polar body extrusion was completed within $12 \mathrm{hr}$ after culturing the oocytes with ETO-CHXM. Some oocytes had two or more polar body (PB)-like fragments, which contained chromatin (Fig. 1a). A higher percentage of the oocytes failed to expel the total chromatin into the polar body when the concentrations of ETO-CHXM were 10 and $25 \mu \mathrm{g} / \mathrm{m} l$ (Table 2). The total chromatin was expelled into the polar bodies (Fig. 1b) at a higher rate when the concentrations of ETO-CHXM were 36 and 50 $\mu \mathrm{g} / \mathrm{m} l$ (Table 2 ). The oocytes with partial chromatin expulsion were those in which part of the chromatin was retained in the cytoplasm while the remaining part was expelled into the polar body (Table 1). Furthermore, the rates of polar body extrusion were similar $(\mathrm{P}>0.05)$ in the treated oocytes and the control.

It is noteworthy that $22.9 \%(51 / 223)$ of the chemically enucleated oocytes cultured in WM + EDTA for $12 \mathrm{hr}$ spontaneously fused to their polar bodies and the combined chromatin complex behaved as a foreign nucleus that
Table 1. Effects of etoposide and cycloheximide concentrations on polar body $(\mathrm{PB})$ extrusion during in vitro maturation of mouse oocytes ${ }^{\text {a) }}$

\begin{tabular}{cccccc}
\hline $\begin{array}{c}\text { Treatment } \\
\mu \mathrm{g} / \mathrm{m} l\end{array}$ & $\begin{array}{c}\text { No. of } \\
\text { oocytes }\end{array}$ & $\begin{array}{c}\text { With PB } \\
(\%)\end{array}$ & $\begin{array}{c}\text { Without PB } \\
(\%)\end{array}$ & $\begin{array}{c}\text { Degenerated } \\
(\%)\end{array}$ & $\begin{array}{c}\text { Others } \\
(\%)\end{array}$ \\
\hline 10 & 149 & $87(58.4)$ & $54(36.2)$ & $2(1.3)$ & $6(4.0)$ \\
25 & 120 & $74(61.7)$ & $35(29.2)$ & $9(7.5)$ & $2(1.7)$ \\
36 & 123 & $81(65.9)$ & $33(26.8)$ & $2(1.6)$ & $7(5.7)$ \\
50 & 130 & $82(63.1)$ & $33(25.4)$ & $7(5.4)$ & $8(6.2)$ \\
Control & 96 & $62(64.6)$ & $34(35.4)$ & $0(0)$ & $0(0)$ \\
\hline
\end{tabular}

a) Data represent a total of three to four replicates.

b) The concentrations presented here are for ETO and CHXM per $\mathrm{m} l$. Control: no treatment.

c) The oocytes that showed two or more PB-like fragments.

Table 2. Effects of etoposide and cycloheximide concentrations on chromatin expulsion into the polar bodies in whole mounts

\begin{tabular}{cccc}
\hline $\begin{array}{c}\text { Treatment } \\
\mu \mathrm{g} / \mathrm{m} l\end{array}$ & $\begin{array}{c}\text { No. of oocytes } \\
\text { examined }\end{array}$ & $\begin{array}{c}\text { Partial expulsion } \\
(\%)\end{array}$ & $\begin{array}{c}\text { Total expulsion } \\
(\%)\end{array}$ \\
\hline 10 & 80 & $19(23.8)$ & $61(76.3)^{\mathrm{b})}$ \\
25 & 48 & $10(20.8)$ & $38(79.2)^{\mathrm{b})}$ \\
36 & 77 & $5(6.5)$ & $72(93.5)^{\mathrm{c})}$ \\
50 & 51 & $1(2.0)$ & $50(98.0)^{\mathrm{c})}$ \\
control & 50 & $50(100)$ & $0(0)^{\mathrm{d}}$ \\
\hline
\end{tabular}

a) The concentrations presented here are for ETO and CHXM per $\mathrm{m} l$. Control: no treatment.

b-d) Values with different superscripts in the same column differ significantly $(\mathrm{P}<0.05)$.

underwent reprogramming (rearrangement on a metaphase plate) and displayed metaphase plate abnormalities (Fig. 2a, $b, c)$. The abnormalities noticed were random dispersion of chromosomes (Fig. 2a), joined chromosomes (Fig. 2b) and chromosomes detached from the spindle (Fig. 2c).

Experiment 2: The fusion rates of the blastomerecytoplast constructs are shown in Table 3 . When the culture interval was $4-8 \mathrm{hr}$, the fusion rate of the blastomerecytoplast constructs was significantly lower $(\mathrm{P}<0.05)$ than those of 15 and $24 \mathrm{hr}$. None of the fused embryos cleaved when the culture interval was $4-8 \mathrm{hr}$. High cleavage rates were obtained when the culture interval of the recipient cytoplasts was 15 to $24 \mathrm{hr}$, but none of them developed beyond the 4-cell stage (Table 4). About 86\% (77/90) of the reconstituted embryos examined displayed metaphase plate abnormalities; only $14.4 \%$ (13/90) showed a normal metaphase plate. The abnormalities noticed were random dispersion of chromosomes (Fig. 3a) which was present in $56.7 \%$ (51/90); joined chromosomes (Fig. 3b) in 20\% (18/ 90), and detached chromosomes (Fig. 3c) in $8.9 \%(8 / 90)$.

Experiment 3: The fusion rates of blastomere-cytoplast constructs were not affected by the cytoplast source, as shown in Table 5. The development of the reconstituted embryos to the blastocyst stage was significantly $(\mathrm{P}<0.001)$ influenced by the cytoplast source. When cytoplasts from bisected oocytes that matured in vivo were used as 

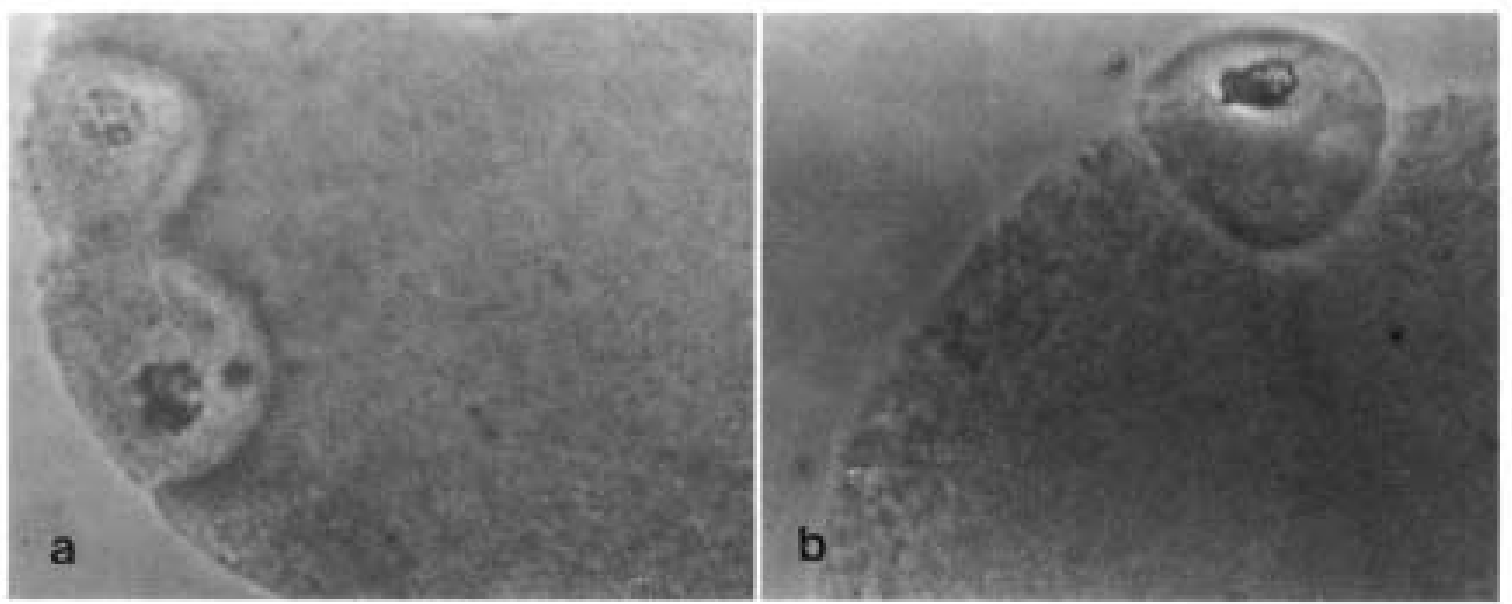

Fig. 1. (a, b) Aceto-orcien-stained chemically enucleated oocytes (cultured in $50 \mu \mathrm{g} / \mathrm{m} l$ etoposide for $2 \mathrm{hr}$ and then with etoposide-cycloheximide (10 $\mu \mathrm{g} / \mathrm{ml}$ each) for $12 \mathrm{hr}$ [× 800]. a) Enucleated oocyte with PB-like fragments. Note that each PBlike fragment contains a separate chromatin fragment. b) Enucleated oocyte with a polar body (note that all chromatin is extruded into the polar body).
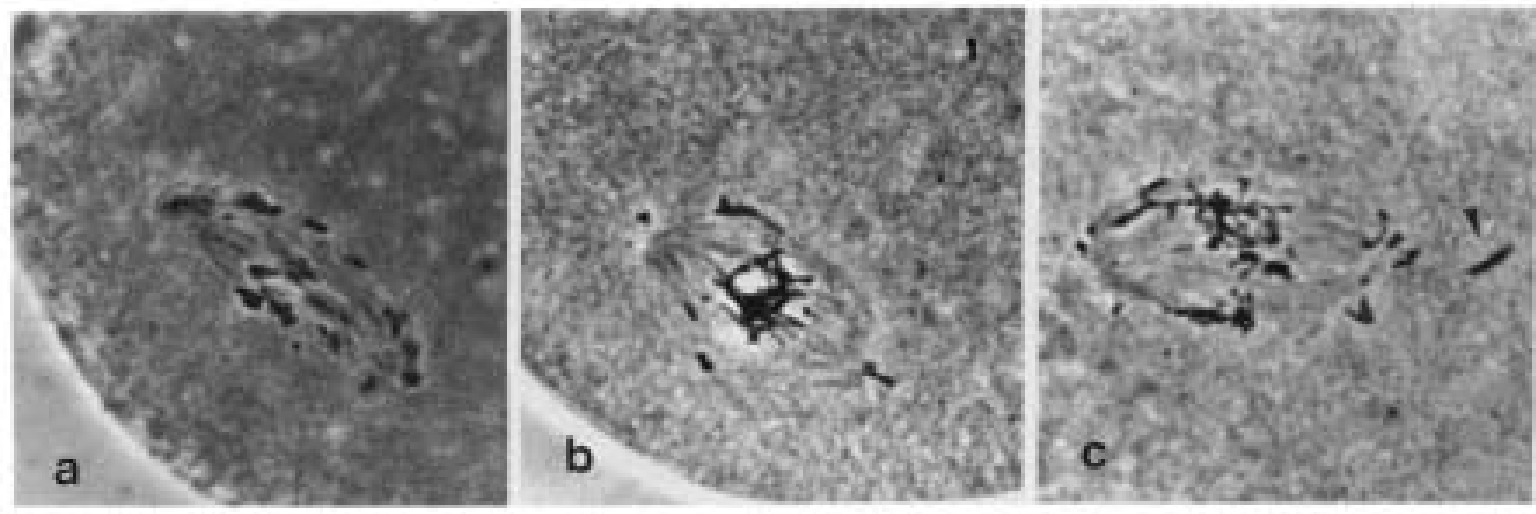

Fig. 2. (a, b, c) Chemically enucleated oocytes with spontaneously fused polar bodies after culture in WM + EDTA for $12 \mathrm{hr}$ [ $\times 800]$. Note the metaphase plate abnormalities. a) Dispersed chromosomes. b) Joined chromosomes. c) Detached chromosomes (see arrow).

Table 3. The influence of the age of chemically enucleated oocytes on fusion rates of aggregated pairs ${ }^{\text {a) }}$

\begin{tabular}{ccc}
\hline Oocyte age $^{\mathrm{b})}$ & No. of embryos treated & No. $(\%)$ of embryos fused \\
\hline $4-8 \mathrm{hr}$ & 64 & $49(76.6)^{\mathrm{c})}$ \\
$15 \mathrm{hr}$ & 122 & $109(89.3)^{\mathrm{d})}$ \\
$24 \mathrm{hr}$ & 83 & $77(92.8)^{\mathrm{d})}$ \\
\hline
\end{tabular}

a) Data were pooled from three to four replicates.

b) Post chemical enucleation age.

c, d) Values with different superscripts in the same column differ significantly $(\mathrm{P}<0.05)$.

recipients, a very high proportion of the reconstituted embryos cleaved, and $33.3 \%$ (13/39) of the cleaved embryos developed to blastocysts. With bisected chemically enucleated oocytes and cytoplasts obtained from bisected oocytes that matured in vitro, however, the rates of cleavage of reconstituted embryos were significantly lower $(\mathrm{P}<0.001)$ compared with single blastomeres of late 2-cell stage embryos. Although cytoplasts from oocytes matured in vivo supported the development of the reconstituted embryos to the blastocyst stage when used as recipients, chemically enucleated oocytes and cytoplasts from oocytes that matured in vitro did not (Table 5).

\section{DISCUSSION}

The results of this study showed that various concentrations of ETO-CHXM did not significantly influence the rates of polar body extrusion. In contrast, the rates of chromatin expulsion were increased significantly by increasing the ETO-CHXM concentration. Concentrations of ETO-CHXM between 36 and $50 \mu \mathrm{g} / \mathrm{m} l$ are optimal for chemical enucleation of mouse oocytes. The results also indicated that recipient cytoplasts from chemically enucleated oocytes were unable to support the development of the reconstituted embryos to blastocysts in vitro. 
Table 4. Development of reconstituted embryos obtained by fusion of chemically enucleated oocytes and blastomeres from late 2-cell stage embryos ${ }^{\text {a) }}$

\begin{tabular}{cccccc}
\hline & & \multicolumn{4}{c}{ No. $(\%)$ of embryos developed to ${ }^{\mathrm{c})}$} \\
\cline { 3 - 6 } $\begin{array}{c}\text { Recipient } \\
\text { oocyte age }^{\mathrm{b})}\end{array}$ & $\begin{array}{c}\text { Embryos } \\
\text { cultured }\end{array}$ & $\begin{array}{c}\text { 2-cell } \\
(24 \mathrm{hr})\end{array}$ & $\begin{array}{c}3-4 \text { cells } \\
(48 \mathrm{hr})\end{array}$ & $\begin{array}{c}\text { Morula } \\
(72 \mathrm{hr})\end{array}$ & $\begin{array}{c}\text { Blastocyst } \\
(96 \mathrm{hr})\end{array}$ \\
\hline $4-8 \mathrm{hr}$ & 44 & $0(0)^{\mathrm{d})}$ & $0(0)^{\mathrm{d})}$ & $0(0)$ & $0(0)$ \\
$15 \mathrm{hr}$ & 102 & $82(80.4)^{\mathrm{e})}$ & $15(14.7)^{\mathrm{e})}$ & $0(0)$ & $0(0)$ \\
$24 \mathrm{hr}$ & 77 & $58(75.3)^{\mathrm{e})}$ & $15(19.5)^{\mathrm{e})}$ & $0(0)$ & $0(0)$ \\
$\mathrm{SB}$ & 119 & $\left.115(96.6)^{\mathrm{f}}\right)$ & $\left.110(92.4)^{\mathrm{f}}\right)$ & $108(90.8)$ & $105(88.2)$ \\
\hline
\end{tabular}

a) Data were pooled from three to four replicates.

b) hr after chemical enucleation.

c) Based on the number of cultured embryos.

d-f) Values with different superscripts in the same column differ significantly $(\mathrm{P}<0.001)$.

SB (control: Single blastomeres from late 2-cell embryos.

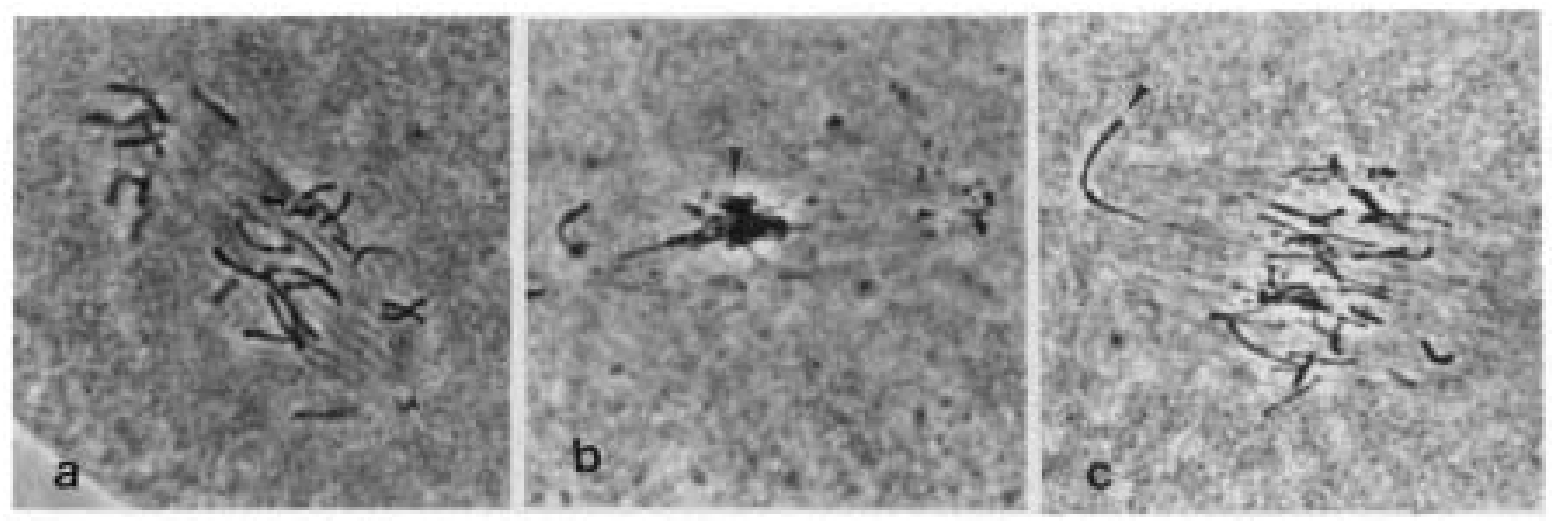

Fig. 3. (a, b, c) Abnormal metaphase plates at about 90 min after fusion of chemically enucleated oocytes with late 2-cell stage blastomeres [ $\times 800]$. Spindles with : a) Dispersed chromosomes; b) Joined chromosomes (see arrow), and c) Detached chromosomes (see arrow).

Table 5. Effect of cytoplasmic source on development of reconstituted embryosa)

\begin{tabular}{lcccccc}
\hline \multirow{2}{*}{$\begin{array}{l}\text { Cytoplast } \\
\text { source }\end{array}$} & $\begin{array}{c}\text { Embryos } \\
\text { treated }\end{array}$ & $\begin{array}{c}\text { No. (\%) } \\
\text { fused }\end{array}$ & \multicolumn{4}{c}{ No. $(\%)$ of embryos developed to ${ }^{\mathrm{b})}$} \\
\cline { 4 - 7 } & & $\begin{array}{c}\text { 2-cell } \\
(\leqq 24 \mathrm{hr})\end{array}$ & $\begin{array}{c}3-4 \text { cells } \\
(\leqq 48 \mathrm{hr})\end{array}$ & $\begin{array}{c}\text { Morula } \\
(\leqq 72 \mathrm{hr})\end{array}$ & $\begin{array}{c}\text { Blastocyst } \\
(\leqq 96 \mathrm{hr})\end{array}$ \\
\hline C. E. O. & 96 & $86(89.6)$ & $73(84.9)^{\mathrm{c})}$ & $12(14.0)^{\mathrm{f})}$ & $0(0)^{\mathrm{f}}$ & $0(0)^{\mathrm{f})}$ \\
IN VITRO & 88 & $80(90.9)$ & $44(55.0)^{\mathrm{d})}$ & $19(23.8)^{\mathrm{f})}$ & $4(5.0)^{\mathrm{f}}$ & $0(0)^{\mathrm{f})}$ \\
IN VIVO & 47 & $41(87.2)$ & $39(95.1)^{\mathrm{c}, \mathrm{e})}$ & $28(68.3)^{\mathrm{h})}$ & $17(41.5)^{\mathrm{h})}$ & $13(31.7)^{\mathrm{h})}$ \\
Control & 98 & - & $\left.96(98.0)^{\mathrm{e}}\right)$ & $91(92.9)^{\mathrm{g})}$ & $90(91.8)^{\mathrm{g})}$ & $89(90.8)^{\mathrm{g})}$ \\
\hline
\end{tabular}

a) Data were pooled from three to four replicates. C. E. O: Chemically enucleated oocytes cultured after enucleation for $15 \mathrm{hr}$ in drug-free WM + EDTA; IN VITRO; in vitro matured oocytes; IN VIVO: in vivo matured oocytes. Control: single blastomere from late 2-cell.

b) Based on the number of fused embryos.

c-g) Values with different superscripts in the same column differ significantly $(\mathrm{P}<0.001)$.

Metaphase I oocytes cultured in $50 \mu \mathrm{g} / \mathrm{m} l$ ETO for $2 \mathrm{hr}$ followed by further culturing in different concentrations of ETO-CHXM for $12 \mathrm{hr}$ extruded polar bodies at a rate similar to that of controls. Our results are broadly similar to those reported by Fulka and Moor [6]. However, the findings of our experiments suggested that perturbing meiosis by these drugs resulted in PB-like fragments in some of the oocytes. The chromatin parts found in the PB-like fragments might migrate to the oocyte periphery due to meiotic perturbation. A similar phenomenon was reported in mitotic cells perturbed in the early mitotic stage [12]. Furthermore, there was no significant difference in the rates of chromatin expulsion when the ETO-CHXM concentrations were 36 and $50 \mu \mathrm{g} / \mathrm{m} l$. The rate of polar body extrusion was not affected by the low concentrations of ETO-CHXM, and since CHXM is used only to elicit polar body extrusion [2], 
the results also suggested that the CHXM concentration could be reduced to $10 \mu \mathrm{g} / \mathrm{m} l$ (Table 1 ). This could partly help to overcome the problems associated with CHXM treatment. The results also showed that the polar bodies of chemically enucleated oocytes occasionally fuse to the cytoplasts when the oocytes were further cultured in ETOCHXM-free medium. Downes et al. [4] reported a similar effect when they used ETO to block topoisomeraze II enzyme in mammalian cells. They found that the daughter cells obtained occasionally fuse to form a single mononucleated cell. The combined chromosomes of the spontaneously fused polar bodies behaved like a foreign nucleus and underwent reprogramming of the metaphase plate, however, the metaphase plates formed were abnormal.

Increasing the culture interval from 8 to $15 \mathrm{hr}$ or $24 \mathrm{hr}$ significantly increased the rates of fusion and cleavage of reconstituted embryos. Since the protein synthesis in chemically enucleated oocytes is inhibited by CHXM [2] at the germinal vesicle breakdown stage, these oocytes may have kept the smooth surface of the cytoplasmic membrane of the germinal vesicle stage [17]. This could explain the low fusion rate when the oocytes were used at 4 to $8 \mathrm{hr}$ after removal from the chemical enucleation medium. The increase in the rate of cleavage may be due to the improvement of the activation response by increasing the culture interval [6]. Chemically enucleated oocytes are reported to have an increasing level of maturation promoting factor (MPF) after the culture interval is increased. This could provide the donor nuclei with enough time and ample amount of MPF for remodeling and reprogramming [6, 7]; however, the fused embryos in the present experiments were not able to develop beyond the 4-cell stage. A very high proportion of the reconstituted embryos $(85.5 \%)$ expressed metaphase plate abnormalities. The number of embryos with abnormalities observed in this study was much higher than that in the report of Fulka et al. [7]. The inability to support development may be explained as a result of a high level of MPF, which leads to metaphase plate abnormalities [7]. The cytostatic factor suggested by Masui and Markert [13] in M II oocyte cytoplasm might also have increased gradually after transfer of the oocytes from ETO-CHXM, and might have participated in hindering the reconstituted embryos to develop. The contributions of the abnormal nucleocytoplasmic ratio $[8,11,15]$ and the toxic effects of ETO-CHXM to poor development must also be considered.

Similarly high fusion rates (around 90\%) were achieved when cytoplasts from oocytes matured in vivo and in vitro, and chemically enucleated oocytes were employed as recipients. These results contrast with those reported by Taniguchi and Kanagawa [26], who reported low rates of fusion $(38.1 \%)$ when they fused cytoplasts from oocytes matured in vivo to late 2-cell stage blastomeres. This discrepancy is presumably due to differences either in the pre-electrofusion treatment or the electrofusion conditions. In the present investigation, the area of attachment between the cytoplasts and the single blastomeres was increased by sucking the blastomere-cytoplast constructs into a narrow pipette. Furthermore, the embryos were precultured in WM + EDTA for 30 to $45 \mathrm{~min}$ and then electrofused with a different protocol [5]. Since the age of the oocytes is reported to influence the activation response [18], the difference in the cleavage rates could be explained on the basis that the age at which the oocytes matured in vitro were used was not a suitable age to activate this kind of oocyte. Only the cytoplasts from oocytes matured in vivo supported the development of the reconstituted embryos to blastocyts. This supports the previous findings of Taniguchi and Kanagawa [26] who reported that the cytoplast source significantly influences the development of reconstituted embryos with nuclei from 2-cell stage embryos. Although the cytoplast volume of the chemically enucleated oocytes was reduced by bisection, in the present study, the development of the reconstituted embryos was not improved. This indicated that some important events that maintain the normal metaphase spindle morphology and determine the ability to support development of donor nuclei from the late 2-cell stage were not achieved in chemically enucleated oocytes under the present conditions.

We conclude that concentrations of ETO between 36 and $50 \mu \mathrm{g} / \mathrm{ml}$ are optimal for chemical enucleation of mouse oocytes. The CHXM concentration could be reduced to 10 $\mu \mathrm{g} / \mathrm{m} l$ without affecting the rate of polar body extrusion. Increasing the age or reducing the cytoplasmic volume of chemically enucleated oocytes did not improve the development of the reconstituted embryos under the present conditions. This was probably due to the high levels of MPF. To investigate the development of reconstituted embryos using chemically enucleated oocytes effectively, however, it is necessary to: (i) investigate the effects of the cytostatic factor, (ii) optimize the activation conditions for chemically enucleated oocytes, and (iii) improve the in vitro maturation conditions.

ACKNOWLEDGMENT. This study was supported by a Grant-in-Aid for Research (No. 0545412) from the Ministry of Education, Science and Culture, Japan.

\section{REFERENCES}

1. Bradshaw, J., Jung, T., Fulka, J. Jr., and Moor, R. M. 1995. UV irradiation of chromosomal DNA and its effects upon MPF and meiosis in mammalian oocytes. Mol. Reprod. Dev. 41: 503-512.

2. Clarke, H. J. and Masui, Y. 1983. The induction of reversible and irreversible chromosome decondensation by protein synthesis inhibition during meiotic maturation of mouse oocytes. Dev. Biol. 97: 291-301.

3. Czolowska, R., Waksmundzka, M., Kubiak, J. Z., and Tarkowski, A. J. 1986. Chromosome condensation activity in ovulated metaphase II mouse oocytes assayed by fusion with interphase blastomeres. J. Cell Sci. 84: 129-138.

4. Downes, C. S., Mullinger, A. M., and Johnson, R. T. 1991. Inhibitors of DNA topoisomerase II prevent chromatid separation in mammalian cells but do not prevent exit from mitosis. Proc. Natl. Acad. Sci. U.S.A. 88: 8895-8899.

5. Elsheikh, A. S., Takahashi, Y., Tanaka, H., Hishinuma, M., 
and Kanagawa, H. 1995. Electrofusion of zona-free mouse embryonic cells in electrolytes and their development in vitro. Jpn. J. Vet. Res. 43: 125-134.

6. Fulka, J. Jr. and Moor, R. M. 1993. Noninvasive chemical enucleation of mouse oocytes. Mol. Reprod. Dev. 34: 427430.

7. Fulka, J. Jr., Notarianni, E., Passoni, L., and Moor, R. M. 1993. Early changes in embryonic nuclei fused to chemically enucleated mouse oocytes. Int. J. Dev. Biol. 37: 433-439.

8. Henery, C. C. and Kaufman, M. H. 1992. Cleavage rate of haploid and diploid parthenogenetic mouse embryos during the preimplantation period. Mol. Reprod. Dev. 31: 258-263.

9. Heyman, Y., Chesne, P., Lebourhis, D., Peynot, N., and Renard, J. P. 1994. Developmental ability of bovine embryos after nuclear transfer based on the nuclear source: In vivo versus in vitro. Theriogenology 42: 695-702.

10. Hogan, B., Constantini, F., and Lacy, E. 1986. Removing the zona pellucida. p. 276. In: Manipulating the Mouse Embryo. Cold Spring Harbor Laboratory, New York.

11. Howlett, S. K., Barton, S. C., and Surani, M. A. 1987. Nuclear cytoplasmic interactions following nuclear transplantation in mouse embryos. Development 101: 915-923.

12. Johnson, R. T., Mullinger, A. M., and Skaer, R. J. 1975. Perturbation of mammalian cell division: human mini segregants derived from mitotic cells. Proc. R. Soc. Lond., B 189: 591-602.

13. Masui, Y. and Markert, C. L. 1971. Cytoplasmic control of nuclear behavior during meiotic maturation of frog oocytes. J. Exp. Zool. 177: 129-146.

14. McGrath, J. and Solter, D. 1983. Nuclear transplantation in the mouse embryo by microsurgery and cell fusion. Science 220: 1300-1302.

15. McGrath, J. and Solter, D. 1986. Nucleocytoplasmic interactions in the mouse embryo. J. Embryol. Exp. Morphol. 97 (Suppl.): 277-289.

16. Mintz, B., Gearhart, J. D., and Guymont, A. O. 1973. Phytohemagglutinin mediated blastomeres aggregation and development of allophenic mice. Dev. Biol. 31: 195-199.

17. Nicosia, S. V., Wolf, D. P., and Mastroianni, L. Jr. 1978. Surface topography of mouse eggs before and after insemination. Gamete Res. 1: 145-155.

18. Pinyopummin, A., Takahashi, Y., Hishinuma, M., and Kanagawa, H. 1993. Development of haploid and diploid mouse parthenogenones: effect of oocyte aging in vivo. Jpn. J. Vet. Res. 41: 81-87.

19. Prather, R. S. and First, N. L. 1990. Cloning embryos by nuclear transfer. J. Reprod. Fertil. 41 (Suppl.): 125-134.

20. Robl, J. M. and Stice, S. L. 1989. Prospects for the commercial cloning of animals by nuclear transplantation. Theriogenology 31: 75-84.

21. Seidel, G. E. Jr. 1983. Production of genetically identical sets of mammals: cloning. J. Exp. Zool. 228: 347-354.

22. Smith, L. C. and Wilmut, I. 1990. Factors affecting the viability of nuclear transplanted embryos. Theriogenology 33: 153164.

23. Stice, S. L. and First, N. L. 1993. Progress towards efficient commercial embryo cloning. Anim. Reprod. Sci 33: 83-98.

24. Surani, M. A. H., Barton, S. C., and Norris, M. L. 1984. Development of reconstituted mouse eggs suggests imprinting of the genome during gametogenesis. Nature (Lond.) 308: $548-550$.

25. Taniguchi, T., Cheong, H. T., and Kanagawa, H. 1992. Development of reconstituted mouse embryos produced from bisected and electrofused pronuclear-stage embryos. Theriogenology 37: 655-663.

26. Taniguchi, T. and Kanagawa, H. 1992. Development of reconstituted mouse embryos produced from the cytoplast of bisected oocytes or pronuclear-stage embryos and single blastomeres of 2-cell stage embryos. Theriogenology 38: 921-934.

27. Tarkowski, A. K. and Rossant, J. 1976. Haploid mouse blasocysts developed from bisected zygotes. Nature (Lond.) 259: 663-665.

28. Tatham, B. G., Dowsing, A. T., and Trounson, A. O. 1995. Enucleation by centrifugation of in vitro-matured bovine oocytes for use in nuclear transfer. Biol. Reprod. 53: 1088-1094.

29. Van De Sandt, J. J. M., Schroeder, A. C., and Eppig, J. J. 1990. Culture medium for mouse oocyte maturation affect subsequent embryonic development. Mol. Reprod. Dev. 25: 164-171.

30. Webb, M., Howlett, S. K., and Maro, B. 1986. Parthenogenesis and cytoskeletal organization in aging mouse eggs. $J$. Embryol. Exp. Morphol. 95: 131-145.

31. Whitten, W. K. 1971. Nutrient requirements for culture of preimplantation embryos in vitro. Adv. Bio. 6: 129-141.

32. Willadsen, S. A. 1986. Nuclear transplantation in sheep embryos. Nature (Lond.) 320: 63-65.

33. Yanagimachi, R. and Yang, C. H. 1990. Preparation of nucleated and anucleated fragments of hamster and mouse eggs by centrifugation. J. Exp. Biol. 253: 220-225.

34. Yang, X. and Anderson, G. B. 1992. Micromanipulation of mammalian embryos: principles, progress and future possibilities. Theriogenology 38: 315-335. 